\title{
A 15-year study on the treatment of undernourished children at a nutrition rehabilitation centre (CREN), Brazil
}

\author{
Mariana BF Fernandes ${ }^{1, *}$, Rossana VM López ${ }^{2}$, Maria P de Albuquerque ${ }^{3}$, \\ Anna C Marchesano', Ana PG Clemente ${ }^{1}$, Vinícius JB Martins ${ }^{1}$ and Ana L Sawaya ${ }^{1}$ \\ 'Departamento de Fisiologia, Disciplina de Fisiologia da Nutrição, Universidade Federal de São Paulo, \\ Vila Clementino, 04023-060 São Paulo, SP, Brazil: ${ }^{2}$ Faculdade de Saúde Pública, Universidade de São Paulo, \\ São Paulo, SP, Brazil: ${ }^{3}$ Centro de Recuperação e Educação Nutricional, Universidade Federal de São Paulo, \\ São Paulo, SP, Brazil
}

Submitted 3 February 2011: Accepted 19 September 2011: First published online 19 October 2011

\begin{abstract}
Objective: To build a life table and determine the factors related to the time of treatment of undernourished children at a nutrition rehabilitation centre (CREN), São Paulo, Brazil.

Design: Nutritional status was assessed from weight-for-age, height-for-age and BMI-for-age Z-scores, while neuropsychomotor development was classified according to the milestones of childhood development. Life tables, Kaplan-Meier survival curves and Cox multiple regression models were employed in data analysis. Setting: CREN (Centre of Nutritional Recovery and Education), São Paulo, Brazil. Subjects: Undernourished children ( $n$ 228) from the southern slums of São Paulo who had received treatment at CREN under a day-hospital regime between the years 1994 and 2009.

Results: The Kaplan-Meier curves of survival analysis showed statistically significant differences in the periods of treatment at CREN between children presenting different degrees of neuropsychomotor development (log-rank $=6 \cdot 621 ; P=0 \cdot 037$ ). Estimates based on the multivariate Cox model revealed that children aged $\geq 24$ months at the time of admission exhibited a lower probability of nutritional rehabilitation (hazard ratio $(\mathrm{HR})=0.49 ; P=0.046$ ) at the end of the period compared with infants aged up 12 months. Children presenting slow development were better rehabilitated in comparison with those exhibiting adequate evolution (HR $=4.48 ; P=0 \cdot 023$ ). No significant effects of sex, degree of undernutrition or birth weight on the probability of nutritional rehabilitation were found.

Conclusions: Age and neuropsychomotor developmental status at the time of admission to CREN are critical factors in determining the duration of treatment.
\end{abstract}

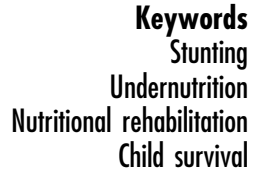

Stunting

Child survival
Undernutrition is characterised by a complex combination of factors including inadequate or insufficient ingestion of food, deficient intake of essential nutrients, unsatisfactory socio-economic conditions, unhealthy living environment, high frequency of infection and poor health care $^{(1,2)}$. Evidently, the longer the exposure to such harmful factors the more damaging the consequences to the nutritional status of the individual. The height-for-age indicator reflects linear growth, and is related to long-term changes in nutritional status and overall health ${ }^{(3)}$. A deficit in this index is associated with cumulative growth retardation indicating chronic undernutrition.

The problem of undernutrition is of global concern since, according to the latest FAO estimates, 925 million people ingest insufficient food to meet their minimum energy requirements, of whom 53 million live in Latin America and the Caribbean ${ }^{(4)}$. In developing countries, approximately 112 million children aged 5 years or less are affected by weight-for-age deficit and $32 \%$ of children in this age group worldwide have been diagnosed with height-for-age deficit $^{(2)}$. Indeed, height-for-age deficit is currently considered the most important nutritional problem faced by developing countries.

In Brazil, $6 \%$ of children aged less than 5 years suffer from height-for-age deficit, while the prevalence of this condition is higher $(8.2 \%)$ among the poorest sector of the population, i.e. in families with a monthly income less than one-quarter of a minimum salary (US\$ 340). Moreover, the prevalence of height-for-age and weight-for-age deficits among children in the $5-9$ years age range is $6 \cdot 8 \%$ and $4 \cdot 1 \%$, respectively ${ }^{(5)}$.

In the last three decades, population growth in Brazilian cities has been intense with the poorest communities 
being concentrated in disorganised areas characterised by precarious housing and sanitation. In the metropolitan areas of Rio de Janeiro and São Paulo, which comprise $11 \cdot 3$ and $18 \cdot 8$ million people, respectively, the rates of population growth in impoverished zones have been much greater than the averages for the urban regions, and presently account for more than $20 \%$ of the inhabitants of Rio de Janeiro and 11-19\% of the inhabitants of São Paulo ${ }^{(6)}$. This situation has led to increased violence, undernutrition and family breakdown, along with a reduction in the level of schooling. In addition, there is considerable evidence indicating that undernutrition in early life results in harmful consequences over the long term, including obesity, CVD and diabetes ${ }^{(7-10)}$.

In order to tackle this problem, the Federal University of São Paulo (UNIFESP) created the Centre of Nutritional Recovery and Education (CREN) in 1994 with the objectives of developing: (i) methodologies for the nutritional recovery of children with respect to weight and, in particular, stature; and (ii) approaches for direct intervention in the complex socio-economic and familial situation of impoverished urban areas.

The aim of the present study was to investigate a cohort of children who had received treatment for undernutrition at CREN and to identify the factors associated with their recovery using the methodology of life table analyses. The influence of the duration of treatment on the outcome was also assessed. To the best of our knowledge, no life table studies have been designed to investigate the nutritional recovery profile of undernourished children.

\section{Subjects and methods}

\section{CREN protocol}

More than 1000 undernourished children are assisted annually by CREN in a day-hospital regime ( $n 50)$, in an out-patient clinic $(n$ 700) or directly in the community ( $n$ 300) depending on the degree of undernutrition and accessibility of the centre. Treatment and follow-up of the children and their families are carried out by a multidisciplinary team that includes paediatricians, nurses, nutritionists, social carers, psychologists, teachers and auxiliary workers.

Children (aged between 0 and 71 months) accepted into the day-hospital regime originate either from impoverished communities (determined by anthropometric field censuses) or from public health units, and comprise those who have been diagnosed with primary undernutrition and who cannot be rehabilitated in out-patient clinics or by home visits. The routine weekday schedule at CREN comprises five daily meals together with recreational and educational activities (including hygiene practices), sleeping time after lunch and periodical medical examinations. The children are clinically monitored every day through the collection of vital signs (temperature, heart and respiratory rate), recall of food intake, and registry of pathological symptoms such as coughing, sneezing, vomiting, presence of rhinorrhoea, and frequency and consistency of faeces. When inflammatory or parasitic processes are detected, the children are treated accordingly. Evolution of stature is assessed monthly, whereas weight is determined weekly in the morning before the first meal. The five daily meals provided at CREN are made up of components that can be readily acquired by the mothers in local shops. The amount of food prescribed covers $100 \%$ of the energy intake recommended by the Dietary Reference Intake ${ }^{(11)}$ appropriate for the age of the child. Furthermore, the children receive protein-rich food that favours the recovery of stature, as well as vitamin supplements (A, C, D and B complex) and prophylactic doses of Fe until they are 24 months old. Children are discharged from CREN and redirected to day nurseries or pre-schools after effective recovery from undernutrition, i.e. when the height-for-age and weight-for-age parameters are normalised $(Z$-score $>-1)$.

\section{Data collection and antbropometric measurements}

Demographic and clinical data were obtained from medical records. Clinical signs were evaluated by a paediatrician, and children presenting other pathologies that contributed to stature deficit were excluded from the study. Data concerning pregnancy, parturition and neonatal incidents were obtained from an anamnesis carried out with the mother. Information regarding gestational age, birth weight and length was obtained from the certificated record of birth provided by the parent or legal guardian. Infants of less than $15 \mathrm{~kg}$ body weight were weighed using a Kratos (Embu, SP, Brazil) digital scale with a maximum capacity of $15 \mathrm{~kg}$ and a precision of $5 \mathrm{~g}$, while for heavier children a Filizola (São Paulo, SP, Brazil) platform scale with a capacity of $150 \mathrm{~kg}$ and a precision of $100 \mathrm{~g}$ was employed. The stature of children younger than 24 months was assessed using a horizontal infantometer (Balmak, Limeira, SP, Brazil) with a maximum dimension of $100 \mathrm{~cm}$ and precision to the nearest $1 \mathrm{~mm}$. For older children, stature was determined using a wall-mounted vertical stadiometer (Wiso, Curitiba, PR, Brazil) with a maximum dimension of $200 \mathrm{~cm}$ and precision to the nearest $0 \cdot 1 \mathrm{~cm}$. Measurements were taken according to published procedures ${ }^{(12)}$ with the participants wearing light clothes and with bare feet. The cephalic perimeter was determined using an inextensible tape positioned on the occipital prominence and over the arch of the eyebrows.

\section{Neuropsychomotor development}

In order to follow the neurodevelopment of the children, a paediatrician carried out an anamnesis and a physical examination with particular attention to the indicators of child development ${ }^{(13)}$. Development was categorised as 
adequate evolution, delayed progress or slow development at school.

\section{Evaluation of nutritional status}

Children were classified with respect to nutritional status on the basis of weight-for-age, height-for-age and BMI-for-age $Z$-scores (WAZ, HAZ and BMIAZ, respectively; calculated using WHO Anthro $2005^{(14)}$ software) according to WHO recommendations ${ }^{(15)}$. Depending on the WAZ and HAZ values, the degree of undernutrition was considered to be mild $(<-1)$, moderate $(<-2)$ or severe $(<-3)$.

\section{Study design, population and statistical analysis}

The current retrospective longitudinal study was based on information contained in the records of children assisted by CREN during the period 1994 to 2009. Details of the project were submitted to, and approved by, the Committee of Ethics in Research of UNIFESP (protocol no. 0375/09). All of the procedures employed complied with the ethical principles contained in the Declaration of Helsinki as stated by the World Medical Association. Written informed consent was obtained from the parents or legal guardians, where appropriate, prior to the commencement of the study. A total of 250 children aged 0-71 months who had received assistance under the dayhospital regime at CREN during the period 1994-2009 were initially selected for study. However, the sample population was reduced by $8.80 \%$ to 228 owing to either incomplete medical records at admission (nine children) or lack of information regarding the follow-up period (thirteen children). One infant died at the beginning of treatment due to multiple organ failure, septicaemia, bronchopneumonia and acute diarrhoea and was included in the study as non-rehabilitated.

Mean values and standard deviations were calculated for continuous variables, while frequencies and proportions were calculated for categorical characteristics. Oneway ANOVA was used in order to compare the mean values of birth weight, length at birth, cephalic perimeter, WAZ, HAZ and BMIAZ between the mildly, moderately and severely undernourished children. The $\chi^{2}$ test was used to evaluate the association between sex, gestational age and age range at the time of admission and the various degrees of undernutrition. All of the children were followed up until their complete rehabilitation or until they left the programme according to age limitation. The variable of interest (the outcome) was recovery from undernutrition, since this parameter reflects factors related to early detection and effectiveness of the treatment. In order to carry out the analysis, the period between the first attendance at CREN and the occasion of discharge after the rehabilitation had been achieved was taken as the time of recovery, and the status variables were 'rehabilitated' or 'non-rehabilitated'. Children who had been discharged from CREN owing to age limitation, those who abandoned the programme and those who had died were classified within the non-rehabilitated group. Life tables were constructed for all the variables, as well as Kaplan-Meier survival curves and log-rank test. Life table analysis investigated the length of treatment according to different variables, and Kaplan-Meier curves analysed statistical differences among them. Univariate and multivariate Cox regression models were constructed in order to evaluate the independent factors relating to rehabilitation of the children ${ }^{(16)}$. Sex, age range, degree of undernutrition, neuropsychomotor development and birth weight were considered in the multivariate analysis. In all tests, the level of significance was set at $P<0 \cdot 005$. Descriptive analyses, comparison tests between groups and life tables were evaluated using the statistical software package PASW Statistics 18 (SPSS Inc., Chicago, IL, USA). Kaplan-Meier curves, log-ranks and Cox regression models were analysed using the statistical software package Intercooled STATA $9 \cdot 2$ for Windows (StataCorp, College Station, TX, USA).

\section{Results}

Within the sample of 228 children who had received assistance under the day-hospital regime at CREN during the period 1994 to 2009 , the male to female ratio was $1: 1$ (Table 1). There was a predominance of girls within the groups presenting mild and moderate undernutrition, while boys predominated within the group exhibiting severe undernutrition $(P=0 \cdot 002)$. The differences between the mildly, moderately and severely undernourished groups regarding the mean values of birth weight and length at birth were statistically significant $(P=0.004$ for both characteristics). Furthermore, cephalic perimeter of children with severe undernutrition was smaller than those within the other two groups.

Comparison of the mean values of WAZ, HAZ and BMIAZ obtained at the time of admission to CREN with those determined at the time of discharge revealed improvements in all undernourished groups, with average increments of 0.667 (SD 0.991), 0.841 (SD 0.983) and 0.184 (SD 1.185), respectively (Table 1 ). Considering the groups individually, the respective mean increments in WAZ, HAZ and BMIAZ were: (i) $0.192(\mathrm{SD} 0.682), 0.252(\mathrm{SD} 0.854)$ and 0.138 (SD 1.040 ) in the mildly undernourished group; (ii) 0.573 (SD 0.772), 0.730 (SD 0.776) and 0.129 (SD 1.061) in the moderately undernourished group; and (iii) 1.041 (SD 1.196), 1.344 (SD 1.027) and 0.276 (SD 1.397) in the severely undernourished group. The differences between the mean increments for the mildly, moderately and severely undernourished groups were statistically significant for WAZ and HAZ $(P<0 \cdot 001)$. In all groups, the ages of the children showed a tendency to concentrate within the ranges of $12-24$ months and $\geq 24$ months, although the differences were not statistically significant $(P=0.694)$.

Children were followed up for 41.54 (sD 29.54) months on average, although $50 \%$ of the children were followed 
Table 1 Anthropometric characteristics of undernourished children ( $n$ 228) from the southern slums of São Paulo, Brazil, treated at CREN during the period 1994-2009

\begin{tabular}{|c|c|c|c|c|c|c|}
\hline \multirow[b]{3}{*}{ Characteristic } & \multicolumn{6}{|c|}{ Degree of undernutrition at the time of admission to CREN } \\
\hline & \multicolumn{2}{|c|}{ Mild } & \multicolumn{2}{|c|}{ Moderate } & \multicolumn{2}{|c|}{ Severe } \\
\hline & $n$ or Mean & $\%$ or SD & $n$ or Mean & $\%$ or SD & $n$ or Mean & $\%$ or SD \\
\hline \multicolumn{7}{|l|}{$\operatorname{Sex}^{*} \dagger$} \\
\hline Male & 23 & $42 \cdot 6$ & 37 & $40 \cdot 2$ & 54 & $65 \cdot 9$ \\
\hline Female & 31 & $57 \cdot 4$ & 55 & $59 \cdot 8$ & 28 & $34 \cdot 1$ \\
\hline Birth weight $(\mathrm{kg}) \ddagger$ & $2 \cdot 77$ & 0.53 & $2 \cdot 64$ & 0.53 & $2 \cdot 42$ & 0.70 \\
\hline Length at birth $(\mathrm{cm}) \ddagger$ & $46 \cdot 42$ & $2 \cdot 94$ & $46 \cdot 64$ & $2 \cdot 53$ & $44 \cdot 50$ & $3 \cdot 82$ \\
\hline Cephalic perimeter $(\mathrm{cm}) \S$ & $36 \cdot 83$ & $5 \cdot 36$ & $36 \cdot 23$ & $6 \cdot 18$ & 33.39 & $5 \cdot 87$ \\
\hline \multicolumn{7}{|l|}{ Gestational age ${ }^{*}||$} \\
\hline Full term & 29 & $74 \cdot 4$ & 62 & $78 \cdot 5$ & 45 & $66 \cdot 2$ \\
\hline Preterm & 10 & $25 \cdot 6$ & 17 & $21 \cdot 5$ & 23 & $33 \cdot 8$ \\
\hline \multicolumn{7}{|l|}{ Weight-for-age $Z$ score } \\
\hline At admission & $-1 \cdot 43$ & 0.53 & $-2 \cdot 11$ & 0.51 & $-3 \cdot 22$ & 0.95 \\
\hline At discharge & $-1 \cdot 23$ & 0.54 & -1.53 & $0 \cdot 75$ & $-2 \cdot 16$ & 0.99 \\
\hline \multicolumn{7}{|l|}{ Height-for-age $Z$ score } \\
\hline At admission & $-1 \cdot 37$ & $0 \cdot 47$ & $-2 \cdot 30$ & $0 \cdot 46$ & $-3 \cdot 69$ & $1 \cdot 15$ \\
\hline At discharge & $-1 \cdot 11$ & 0.92 & $-1 \cdot 56$ & $0 \cdot 82$ & $-2 \cdot 29$ & $1 \cdot 12$ \\
\hline \multicolumn{7}{|l|}{ BMI-for-age $Z$ score } \\
\hline At admission ${ }^{\star *}$ & $-0 \cdot 90$ & $0 \cdot 87$ & -0.98 & $0 \cdot 84$ & $-1 \cdot 27$ & $1 \cdot 50$ \\
\hline At dischargett & $-0 \cdot 77$ & 0.94 & $-0 \cdot 85$ & 0.99 & $-1 \cdot 00$ & 1.02 \\
\hline \multicolumn{7}{|c|}{ Age range at the time of admission (months) ${ }^{\star} \neq \ddagger$} \\
\hline $0-<12$ & 13 & $24 \cdot 1$ & 26 & $28 \cdot 3$ & 24 & $29 \cdot 3$ \\
\hline $12-<24$ & 16 & $29 \cdot 6$ & 26 & $28 \cdot 3$ & 29 & $35 \cdot 4$ \\
\hline$\geq 24$ & 25 & $46 \cdot 3$ & 40 & $43 \cdot 5$ & 29 & $35 \cdot 4$ \\
\hline
\end{tabular}

CREN, Centre of Nutritional Recovery and Education.

*Values are presented as $n$ and \%.

Significant differences between the three groups were determined by the $\chi^{2}$ test or ANOVA at $P<0.005:+\chi^{2}$ test $(P=0.002)$; ANOVA $(P=0.004)$; $\S$ ANOVA

$(P=0.303) ; \| \chi^{2}$ test $(P=0.240) ; \uparrow$ ANOVA $(P<0.001) ;{ }^{* *}$ ANOVA $(P=0.114) ;$ t+ANOVA $(P=0.418) ;$ † ANOVA $(P=0.694)$.

Table 2 Follow-up time of undernourished children $(n$ 228) from the southern slums of São Paulo, Brazil, treated at CREN during the period 1994-2009

\begin{tabular}{lllll}
\hline & \multicolumn{4}{c}{ Follow-up time (months) } \\
\cline { 3 - 5 } Variable & Mean & SD & Median & Minimum-maximum \\
\hline Degree of undernutrition at the time of admission to CREN & & & & \\
$\quad$ Mild & $45 \cdot 23$ & $34 \cdot 31$ & $38 \cdot 83$ & $1 \cdot 20-124 \cdot 63$ \\
$\quad$ Moderate & $39 \cdot 88$ & $28 \cdot 26$ & $33 \cdot 93$ & $0 \cdot 60-118 \cdot 73$ \\
$\quad$ Severe & $40 \cdot 98$ & $27 \cdot 68$ & $39 \cdot 70$ & $0 \cdot 43-107 \cdot 57$ \\
All groups & 41.54 & $29 \cdot 54$ & $35 \cdot 17$ & $0 \cdot 43-124 \cdot 63$ \\
\hline
\end{tabular}

CREN, Centre of Nutritional Recovery and Education.

up for $35 \cdot 17$ months. No differences were found for the follow-up time among the groups with different degrees of undernutrition (Table 2).

The descriptive life table (Table 3) corresponding to the length of treatment received at CREN until complete rehabilitation had been achieved revealed that $98 \%$ of children remained undernourished after 1 year. The percentage of children remaining undernourished diminished quite considerably after 5 years of treatment (66\%), implying that, at this time, $34 \%$ of the sample population achieved normal weight and stature. The life table, which was also stratified according to the characteristics of the sample population, shows that, in general, the probability of remaining undernourished was lower for girls than for boys. Moreover, the likelihood of rehabilitation varied among the age groups. Thus, after 3 or more years of treatment, the probability of remaining undernourished was lower for children up to 12 months old than for those in the age ranges of $12-23$ months and $\geq 24$ months. Moderately undernourished children presented the lowest probability of remaining undernourished after 5 years of treatment, whereas the probabilities were similar in the mildly and severely undernourished groups. Regarding neuropsychomotor development, the probability of remaining undernourished after 5 years of treatment was slightly higher among children presenting adequate advancement in comparison with those presenting delayed progress. The average age of children with delayed neuropsychomotor development ( $n$ 33) was $22 \cdot 81$ (SD 16.72) months, and $51.5 \%$ of this group presented a severe degree of undernourishment. The probability of children who received frequent medication to remain undernourished was lower 
Table 3 Life table corresponding to the length of treatment of undernourished children ( $n$ 228) from the southern slums of São Paulo, Brazil, treated at CREN during the period 1994-2009

\begin{tabular}{|c|c|c|c|c|c|c|}
\hline \multirow[b]{2}{*}{ Variable } & \multicolumn{6}{|c|}{ Probability of remaining undernourished after treatment for } \\
\hline & 6 months & 1 year & 2 years & 3 years & 4 years & 5 years \\
\hline \multicolumn{7}{|l|}{ Sex } \\
\hline Male & 0.99 & 0.99 & 0.94 & 0.87 & $0 \cdot 79$ & 0.69 \\
\hline Female & $1 \cdot 00$ & 0.97 & 0.93 & 0.84 & 0.73 & 0.63 \\
\hline \multicolumn{7}{|l|}{ Gestational age } \\
\hline Full term & 0.99 & 0.98 & 0.94 & 0.83 & 0.74 & 0.64 \\
\hline Preterm & $1 \cdot 00$ & 0.98 & 0.93 & 0.90 & $0 \cdot 74$ & $0 \cdot 65$ \\
\hline \multicolumn{7}{|l|}{ Age range (months) } \\
\hline $0-<12$ & $1 \cdot 00$ & 1.00 & 0.94 & 0.77 & 0.64 & 0.49 \\
\hline $12-<24$ & $1 \cdot 00$ & 0.97 & 0.93 & 0.89 & 0.73 & $0 \cdot 68$ \\
\hline$\geq 24$ & 0.99 & 0.98 & 0.93 & 0.90 & 0.90 & 0.80 \\
\hline \multicolumn{7}{|l|}{ Degree of undernutrition } \\
\hline Mild & $1 \cdot 00$ & 0.96 & 0.93 & $0 \cdot 82$ & $0 \cdot 73$ & 0.73 \\
\hline Moderate & 0.99 & 0.98 & 0.91 & 0.79 & 0.69 & 0.55 \\
\hline Severe & $1 \cdot 00$ & $1 \cdot 00$ & 0.97 & 0.95 & $0 \cdot 85$ & 0.73 \\
\hline \multicolumn{7}{|l|}{ Vaccination } \\
\hline Followed scheme & 0.99 & 0.98 & 0.96 & 0.86 & $0 \cdot 76$ & 0.66 \\
\hline Late & 1.00 & 1.00 & 0.80 & 0.73 & 0.73 & 0.63 \\
\hline \multicolumn{7}{|l|}{ Neuropsychomotor development } \\
\hline Adequate evolution & 0.99 & 0.98 & 0.96 & 0.85 & $0 \cdot 75$ & 0.67 \\
\hline Delayed progress & $1 \cdot 00$ & 0.97 & 0.90 & 0.90 & 0.80 & 0.56 \\
\hline Slow development at school & $1 \cdot 00$ & $1 \cdot 00$ & $0 \cdot 83$ & 0.39 & $-^{\star}$ & $-^{*}$ \\
\hline \multicolumn{7}{|l|}{ Hospital admissions } \\
\hline No & $1 \cdot 00$ & 0.98 & 0.96 & 0.86 & $0 \cdot 74$ & 0.64 \\
\hline Yes & 0.99 & 0.99 & 0.93 & 0.85 & $0 \cdot 76$ & 0.63 \\
\hline \multicolumn{7}{|l|}{ Previous diseases } \\
\hline No & $1 \cdot 00$ & 0.98 & 0.98 & 0.91 & $0 \cdot 81$ & 0.64 \\
\hline Yes & 0.99 & 0.97 & 0.90 & 0.82 & 0.69 & 0.63 \\
\hline \multicolumn{7}{|l|}{ Frequent use of medicines } \\
\hline No & 0.99 & 0.97 & 0.96 & 0.85 & $0 \cdot 75$ & 0.62 \\
\hline Yes & $1 \cdot 00$ & 0.98 & 0.92 & 0.82 & 0.65 & 0.55 \\
\hline \multicolumn{7}{|c|}{ Family history of protein-energy undernutrition } \\
\hline No & $1 \cdot 00$ & 0.89 & 0.89 & 0.89 & 0.45 & 0.45 \\
\hline Yes & $1 \cdot 00$ & 0.98 & 0.92 & 0.85 & 0.77 & 0.71 \\
\hline Overall values & 1.00 & 0.98 & 0.93 & 0.85 & 0.75 & 0.66 \\
\hline
\end{tabular}

CREN, Centre of Nutritional Recovery and Education.

${ }^{*}$ Probability could not be determined owing to an insufficient number of cases.

in comparison with those who were not often medicated. The status of the parents and siblings also influenced the probability of a child to remain undernourished, such that the likelihood of undernourishment was higher when close relatives were themselves undernourished.

Further analyses were done to investigate statistical differences of the above variables by using the curves of survival analysis constructed according to the productlimit method of Kaplan-Meier (Fig. 1). Statistically significant differences were found in the periods of treatment at CREN between children presenting different degrees of neuropsychomotor development $(P=0 \cdot 037$; log-rank $=$ 6.621). In contrast, there were no significant differences between the recovery from undernutrition curves with respect to sex, gestational age, age range, degree of undernutrition, vaccination, hospital admissions, previous diseases, frequent use of medications or record of family history of undernourishment (data not shown).

The results obtained from multivariate Cox regression analysis are shown in Table 4, in which only the primary variables sex, age, degree of undernutrition, neuropsychomotor development and birth weight are presented since information concerning other variables was incomplete. Children aged $\geq 24$ months at the time of admission exhibited a reduction in the probability of undernutrition at the end of the period of $51 \%$ compared with children aged $0-<12$ and $12-23$ months $(P=0 \cdot 046)$. In contrast, children aged between 12 and 23 months at the time of admission showed a probability of recovery of $30 \%$ compared with infants less than 12 months, although the difference in the values of the hazard ratios was not statistically significant. Children with slow development presented a higher probability of rehabilitation ( 4.48 times more) in comparison with those exhibiting adequate evolution. There were no differences between the groups with respect to birth weight.

\section{Discussion}

\section{Duration of treatment}

Classical studies concerning treatments carried out at nutritional rehabilitation centres in developing countries during the period 1950-1970 revealed that most children taken into such programmes presented severe undernutrition. 


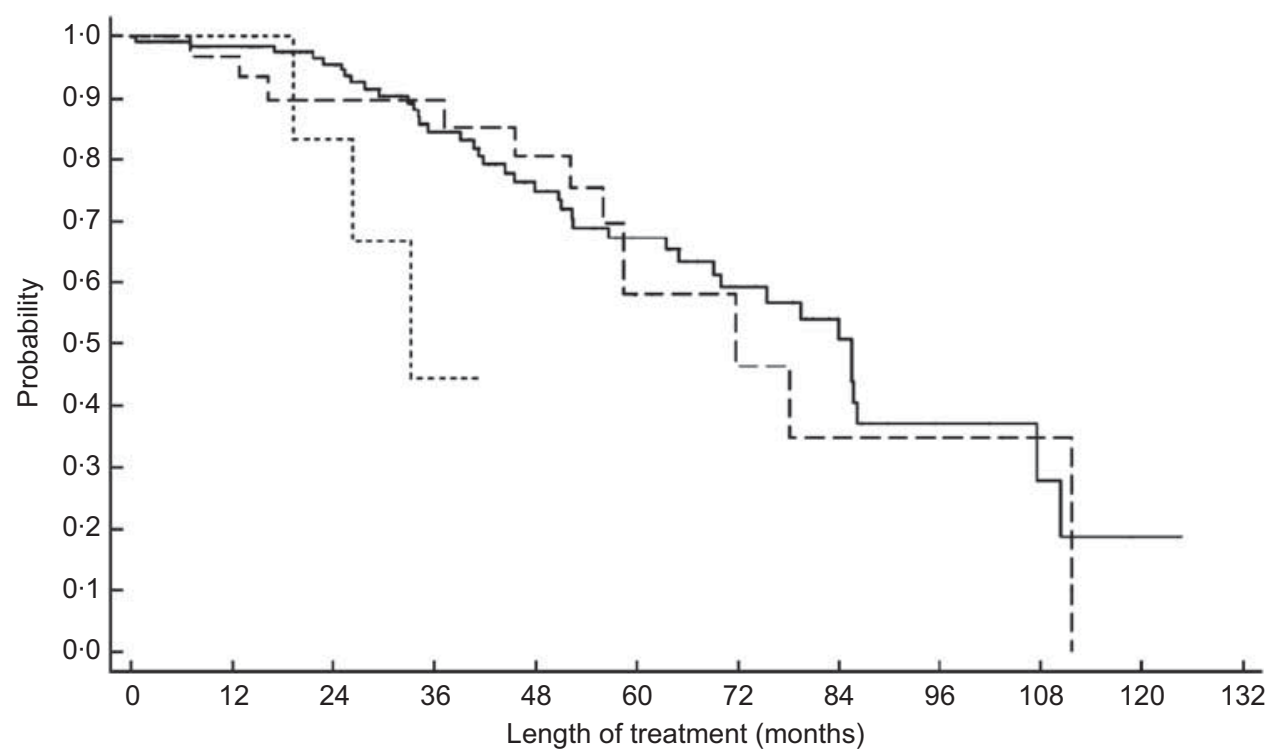

Fig. 1 Kaplan-Meier survival curves relating the probability of remaining undernourished to the time of treatment at CREN of children presenting different degrees of neuropsychomotor development $(-$, adequate evolution; - - -, delayed progress; - - -, slow development at school). Undernourished children ( $n 228)$ from the southern slums of São Paulo, Brazil who had received treatment at CREN (Centre of Nutritional Recovery and Education) under a day-hospital regime between the years 1994 and 2009 (log-rank $=6.621 ; P=0.037)$

Table 4 Multivariate Cox regression analysis relating to the rehabilitation or non-rehabilitation of undernourished children ( $n$ 228) from the southern slums of São Paulo, Brazil, treated at CREN during the period 1994-2009

\begin{tabular}{|c|c|c|c|c|c|c|c|c|}
\hline \multirow[b]{3}{*}{ Characteristic } & \multicolumn{4}{|c|}{ Nutritional status* } & \multirow[b]{3}{*}{$\mathrm{HR}$} & \multirow[b]{3}{*}{ Adjusted HR } & \multirow[b]{3}{*}{$P$ valuet } & \multirow[b]{3}{*}{$95 \% \mathrm{Cl}\left(\mathrm{HR}_{\text {adjusted }}\right.$} \\
\hline & \multicolumn{2}{|c|}{ Non-rehabilitated (n 113) } & \multicolumn{2}{|c|}{ Rehabilitated ( $n$ 54) } & & & & \\
\hline & $n$ & $\%$ & $n$ & $\%$ & & & & \\
\hline \multicolumn{9}{|l|}{ Sex } \\
\hline Male & 63 & $55 \cdot 75$ & 19 & $35 \cdot 19$ & 1.00 & 1.00 & & \\
\hline Female & 50 & $44 \cdot 25$ & 35 & $64 \cdot 81$ & $1 \cdot 11$ & $1 \cdot 23$ & 0.517 & $0 \cdot 66,2 \cdot 30$ \\
\hline \multicolumn{9}{|l|}{ Age range (months) } \\
\hline $0-<12$ & 27 & $23 \cdot 56$ & 19 & $35 \cdot 19$ & $1 \cdot 00$ & $1 \cdot 00$ & & \\
\hline $12-23$ & 38 & $29 \cdot 31$ & 19 & $35 \cdot 19$ & 0.68 & $0 \cdot 70$ & 0.308 & $0.35,1.39$ \\
\hline$\geq 24$ & 48 & $47 \cdot 13$ & 16 & $29 \cdot 63$ & 0.49 & 0.49 & 0.046 & $0.25,0.99$ \\
\hline \multicolumn{9}{|l|}{ Degree of undernutrition } \\
\hline Mild & 26 & $23 \cdot 01$ & 13 & $24 \cdot 07$ & 1.00 & 1.00 & & \\
\hline Moderate & 44 & 38.94 & 26 & $48 \cdot 15$ & $1 \cdot 24$ & $1 \cdot 65$ & $0 \cdot 154$ & $0 \cdot 83,3 \cdot 28$ \\
\hline Severe & 43 & 38.05 & 15 & $27 \cdot 78$ & $0 \cdot 80$ & 1.04 & 0.929 & $0 \cdot 45,2 \cdot 39$ \\
\hline \multicolumn{9}{|l|}{ Neuropsychomotor development } \\
\hline Adequate evolution & 86 & $76 \cdot 11$ & 40 & $74 \cdot 07$ & $1 \cdot 00$ & $1 \cdot 00$ & & \\
\hline Slow development at school & 6 & $5 \cdot 31$ & 3 & $5 \cdot 56$ & $4 \cdot 38$ & $4 \cdot 48$ & 0.023 & $1 \cdot 23,16 \cdot 31$ \\
\hline Delayed progress & 21 & $18 \cdot 58$ & 11 & $20 \cdot 37$ & $1 \cdot 19$ & 1.09 & $0 \cdot 823$ & $0.53,2 \cdot 24$ \\
\hline \multicolumn{9}{|l|}{ Birth weight $(\mathrm{kg})$} \\
\hline Mean & $2 \cdot 54$ & & $2 \cdot 66$ & & $1 \cdot 21$ & $1 \cdot 02$ & 0.925 & $1 \cdot 61,1 \cdot 71$ \\
\hline SD & $0 \cdot 61$ & & $0 \cdot 60$ & & & & & \\
\hline
\end{tabular}

CREN, Centre of Nutritional Recovery and Education; HR, hazard ratio.

*Information available for 167 children.

tMeans adjusted for sex, age range, degree of undernutrition, neuropsychomotor development and birth weight.

The average age of the children at admission was 12 months in general, and almost all exhibited marasmus or kwashiorkor. The time required for the nutritional rehabilitation was about 3 months. At that time, the criterion for the diagnosis of nutritional recovery was based on the WAZ index $(\geq-2)$ alone $e^{(17-20)}$ and the aim of the intervention was to reduce mortality rate. However recent studies have underlined that nutritional management during rehabilitation should take into account long-term health and bring about a gain in stature in order to prevent the risk of noncommunicable diseases in adulthood ${ }^{(1,21,22)}$. The duration of the treatment at CREN is extended because it includes both stature and weight recovery, as well as educational intervention to the family. In this respect, studies involving 
children who had been discharged from CREN for at least 3 years showed that rehabilitated individuals presented normal body composition and no alterations in the glucose and insulin metabolism that had been previously described in stunted individuals. In addition, the nutritional education was effective and good food habits persisted after discharge from CREN, even though the families continued to live in poverty $^{(23,24)}$.

Tanner et al. ${ }^{(25)}$ recommend that good measurements of linear growth require intervals of 6 months to 1 year between analyses. Based on this proposal, the status of recovery was estimated only for children who had undertaken treatment at CREN for at least 6 months. The results presented herein demonstrate that the probability of a child remaining undernourished diminished as the length of treatment increased. Additionally, the length of treatment at CREN was based on recovery of stature deficit according to the cut-off point HAZ $>-1$.

A previous publication involving a smaller sample of undernourished children treated at CREN showed 67.9\% nutritional recovery when both HAZ and WAZ were taken into account and $92.5 \%$ recovery when at least one of these indicators was considered ${ }^{(26)}$. Those results indicated that a high prevalence of recovery can be obtained when children complete the treatment at CREN. In the present study, the totality of individuals assisted by CREN at the day-hospital was investigated and fewer children (34\%) recovered from weight and height deficit. This discrepancy arises because the survival analysis of the dynamic cohort of children assisted by CREN during the period 1994-2009 included censored cases (70.6\%) comprising individuals who had abandoned the programme mainly because they had moved to other locations. A high rate of family instability was also detected and this interfered with the progress of the treatment and its duration.

The present study aimed to assess the progress of the undernourished children assisted by CREN during the 15-year period and is the first study to use the life table methodology to investigate the recovery of undernourished children. There were, however, two important limitations for the study: (i) only a small number of individuals had complete records; and (ii) there was a lack of consistency in the manner in which the questionnaires were completed by the professionals at CREN and this made the data collection difficult.

\section{Age of children}

Evidence exists in the literature to suggest that age and nutritional status at the beginning of treatment are determining factors in the promotion of linear catch-up, such that delayed beginning of the treatment reduces the chances of recovering linear growth ${ }^{(27,28)}$. The present study revealed that at the date of admission to CREN, the average age of the population was 24.45 months, a stage in life in which it is more difficult to reverse stature deficit.
In spite of this, it was observed that increases in HAZ were greater than in WAZ. The positive effects were observed even in children aged $\geq 24$ months at the time of admission, although the magnitude of such recovery was inferior to that shown by younger individuals.

\section{Recovery patterns}

The present study showed that stature deficit was the most prevalent nutritional challenge among the moderately and severely undernourished children assisted by CREN, confirming the hypothesis proposed by Black et $a l^{(2)}$ who stated that urban poverty impairs linear growth more than weight. On the other hand, the increments in stature and weight of the severely undernourished children were superior to those of children presenting milder forms of undernutrition. These results are in agreement with the findings of Goulart et $a l^{(26)}$ who studied the effects of a food supplementation programme on the recovery of undernourished children and of those at nutritional risk, and found that recovery levels were higher when the initial deficit was greater.

\section{Neuropsychomotor development}

Undernutrition is associated with cognitive impairment in children and adolescents, delayed progress at school, gaps in school attendance, incomplete education, decreased productivity, reduced stature and delayed motor development in adulthood ${ }^{(29-31)}$. Poverty and social vulnerability are also risk factors for delayed language acquisition in children ${ }^{(32)}$. Children who were undernourished during intra-uterine life tend to perform badly in intelligence tests and to present a lower learning capacity, and such impediment is more accentuated when undernutrition extends into early postnatal life ${ }^{(33)}$. Additionally, according to Landon et $a l^{(34)}$, birth weight is positively associated with cognitive abilities in children, although environmental factors may weaken this relationship as time goes by. On the other hand, the beneficial effects of stature rehabilitation during infancy have been observed in a number of studies. In Guatemala, food supplementation during infancy increased the attendance of girls at school by one to two years ${ }^{(35)}$, while a study involving a rural population in Zimbabwe established an association between HAZ increment in pre-school children and the level of education in young adults, with an additional $3.4 \mathrm{~cm}$ height corresponding to 0.85 additional grades of schooling ${ }^{(36)}$. More recently, it has been demonstrated that undernourished children who had recovered in stature exhibited similar language and cognitive performances as non-stunted children ${ }^{(37)}$. These findings show a positive impact of nutritional rehabilitation and linear catch-up on neuropsychomotor development.

The results presented herein demonstrate that undernourished children with delayed neuropsychomotor development rehabilitated faster than those whose progress was adequate. These children exhibited a more severe 
degree of undernourishment at the time of admission to CREN and were younger. We believe, therefore, that the positive results obtained with children presenting delayed neuropsychomotor development are associated with the greater severity of their nutritional condition as well as their lower age at admission compared with the other groups.

\section{Conclusions}

Analysis of child survival revealed that age and neuropsychomotor developmental status at the time of admission to CREN were critical factors in determining the duration of treatment. These findings demonstrate the importance of early nutritional recovery, and indicate that the treatment should preferentially start before the age of 24 months. Linear catch-up has also been achieved for older children at CREN, but at a lower speed and after an extended period of treatment. Further investigations are needed in order to establish the long-term positive impact of nutritional rehabilitation on weight and stature.

\section{Acknowledgements}

The work was carried out at the Universidade Federal de São Paulo. The study was supported by CAPES (Coordenação de Aperfeiçoamento de Pessoal de Nivel Superior). The authors declare that they have no conflicts of interest. The authors contributed to the work in the following manner: M.B.F.F. was responsible for conducting all of the fieldwork, manuscript preparation and participated in all phases of the study. A.C.M., A.P.G.C. and V.J.B.M. played a lead role in data collection. R.V.M.L. and M.P.A. assisted with statistical analysis of the data and preparing the manuscript. A.L.S. designed the original study, supervised all phases of the study and was responsible for revision of the final manuscript. All authors have approved the publication of the article in its present form. The authors wish to thank the staff at CREN as well as the participants and their families for their important contributions to this study.

\section{References}

1. Sawaya AL (2006) Desnutrição: Conseqüências em longo prazo e efeitos da recuperação nutricional. Estud Av 20, 147-158.

2. Black RE, Allen LH, Bhutta ZA et al. for the Maternal and Child Undernutrition Study Group (2008) Maternal and child undernutrition: global and regional exposures and health consequences. Lancet 371, 243-260.

3. Waterlow JC \& Tomkins AM (1996) Nutrición e infección. In Malnutrición Proteico-energética. Publicación Científica no. 555, pp. 356-400 [JC Waterlow, editor]. Washington, DC: Organización Panamericana de la Salud.

4. Food and Agriculture Organization of the United Nations (2010) The State of Food Insecurity in the World. Rome: FAO/Economic and Social Development Department; available at http://typo3.fao.org/fileadmin/templates/ publications/ppt/SOFI_Presentation2010_en.ppt\#1
5. Instituto Brasileiro de Geografia e Estatística (2010) Pesquisa de Orçamentos Familiares 2008-2009- Despesas, Rendimentos e Condições de Vida. Rio de Janeiro, RJ: IBGE.

6. Saglio-Yatzimirsky MC (2009) Politicas urbanas, territórios e exclusão social: as favelas nas grandes cidades - Brasil e Índia. Estud Av 23, 219-222.

7. Barker DJ (1999) The fetal origins of cardiovascular disease. Ann Intern Med 130, 322-324.

8. Franco MCP, Christofalo DMJ, Sawaya AL et al. (2006) Effects of low birth in 8- to 13-year-old children: implications in endothelial function and uric acid levels. Hypertension $\mathbf{4 8}$, $45-50$.

9. Barquera S, Peterson KE, Must A et al. (2007) Coexistence of maternal central adiposity and child stunting in Mexico. Int J Obes (Lond) 31, 601-607.

10. Langley-Evans SC (2009) Nutritional programming of disease: unravelling the mechanism. J Anat 215, 36-51.

11. Otten JJ, Hellwig JP \& Meyers LD (2006) DRI, Dietary Reference Intakes: The Essential Guide to Nutrient Requirements. Washington, DC: National Academies Press.

12. Lohman TJ, Roche AF \& Martorell R (1988) Anthropometric Standardization Reference Manual. Champaign, IL: Human Kinetics Books.

13. Figueiras AC, de Souza ICN, Rios VG et al. (2005) Manual para Vigilância do Desenvolvimento Infantil no Contexto da AIDPI. Washington, DC: Organização Pan-Americana da Saúde; available at http://www.bvsde.paho.org/bvsacd/ cd61/vigilancia.pdf

14. World Health Organization (2005) WHO Anthro 2005 Software and Macros. http://www.who.int/childgrowth/ software/software_mobile/en/index.html (accessed April 2010).

15. World Health Organization Multicentre Growth Reference Study Group (2006) WHO child growth standards based on length/height, weight and age. Acta Paediatr Suppl 450, 76-85.

16. Kleinbaum DG (1995) Survival Analysis: A Self-learning Text. New York: Springer.

17. Monckeberg GF (1988) Desnutrición Infantil: Fisiopatología Clínica Tratamiento y Prevención, Nuestra Experiencia e Contribuición. Santiago: Instituto de Nutrición y Tecnología de los Alimentos, Universidad de Chile.

18. Massa E, Lopez de Romana G, Kanashiro HC et al. (1980) A nutrition rehabilitation unit for the treatment of severe infant malnutrition. Arch Latinoam Nutr 30, 417-431.

19. Pizarro T, Rodriguez L \& Atalah E (2003) Admission diagnosis and nutritional evolution of the beneficiaries of 'Corporación para la Nutricion Infantil - CONIN'. Rev Med Chil 131, 1031-1036.

20. Colecraft EK, Marquis GS, Bartolucci AA et al. (2004) A longitudinal assessment of the diet and growth of malnourished children participating in nutrition rehabilitation centres in Accra, Ghana. Public Health Nutr 7, 487-494.

21. Weisstaub SG \& Araya M (2003) Nutritional recovery. An unresolved challenge. Rev Med Chil 131, 213-219.

22. Neves J, Martins PA, Sesso R et al. (2006) Malnourished children treated in day-hospital or outpatient clinics exhibit linear catch-up and normal body composition. J Nutr 136, 648-655.

23. Prader A (1978) Catch-up growth. Postgrad Med J 54, Suppl. 1, 133-146.

24. Walker SP \& Golden MH (1988) Growth in length of children recovering from severe malnutrition. Eur J Clin Nutr 42, 395-404.

25. Tanner JM, Whitehouse RH \& Takaishi M (1966) Standards from birth to maturity for height weight velocity and weight velocity: British children 1965 Part II. Arch Dis Child 41, 613-635.

26. Goulart RM, Junior IF \& Souza MFM (2007) Recuperação nutricional de crianças desnutridas e em risco nutricional 
em programa de suplementação alimentar no municipio de Mogi das Cruzes, São Paulo, Brasil. Cad Saude Publica 23, 147-156.

27. Alves-Vieira MF, Ferraro AA, do Nascimento-Souza MH et al. (2010) Height and weight gains in a nutrition rehabilitation day-care service. Public Health Nutr 13, $1505-1510$

28. Martins VJB, Martins PA, das Neves J et al. (2008) Children recovered from malnutrition exhibit normal insulin production and sensitivity. BrJ Nutr 99, 297-302.

29. Caulfield LE, Richard SA, Rivera JA et al. (2006) Stunting, wasting, and micronutrient deficiency disorders. In Disease Control Priorities in Developing Countries, 2nd ed., pp. 551-567 [DT Jamison, JG Breman, AR Measham et al., editors]. Washington, DC: Oxford University Press.

30. Grantham-McGregor S, Cheung YB, Cueto S et al. (2007) Developmental potential in the first 5 years for children in developing countries. Lancet 369, 60-70.

31. Victora CG, Adair L, Fall C et al. (2008) Maternal and child undernutrition: consequences for adult health and human capital. Lancet 371, 340-357.

32. De Moraes MW, Weber APR, Oliveira-Santos MC et al. (2010) Teste de Denver II: avaliação do desenvolvimento de crianças atendidas no ambulatório do Projeto Einstein na Comunidade de Paraisópolis. Einstein 8, 149-153.

33. Grantham-McGregor S (1995) A review of studies of the effect of severe malnutrition on mental development. J Nutr 125, Suppl. 8, 2233S-2238S.

34. Landon J, Davison M \& Breier B (2006) The developmental environment: influences on subsequent cognitive function and behaviour. In Developmental Origins of Health and Disease, pp. 370-378 [P Gluckman and M Hanson, editors]. Cambridge: Cambridge University Press.

35. Maluccio JA, Hoddinott J, Behrman JR et al. (2006) The Impact of Nutrition During Early Childhood on Education among Guatemalan Adults. Economics Discussion Paper no. 06-14. Middlebury, VT: Department of Economics, Middlebury College.

36. Alderman H, Hoddinott J \& Kinsey B (2004) Long Term Consequences of Early Childhood Malnutrition. HiCN Working Papers no. 09. Brighton: Households in Conflict Network, University of Brighton; available at http:// www.hicn.org/papers/wp09.pdf

37. Crookston BT, Penny ME, Alder SC et al. (2010) Children who recover from early stunting and children who are not stunted demonstrate similar levels of cognition. J Nutr 140, 1996-2001. 